\title{
Integrating A Project Management Approach To E-Business Application Course
}

Kuan C. Chen, Purdue University Calumet

Keh-Wen "Carin” Chuang, Purdue University North Central

\begin{abstract}
Teaching students project managements requires a hands-on approach. Incorporating project management concepts and processes into a student team Web development project adds a dimension that exposes students to the realities of effective Web development. This paper will describe the project management approach used in a Web development course in which students build complete Websites. Based upon the written evaluations included with the final project documentation, students feel this project is the most valuable learning experience of the course. Furthermore, a positive relationship is established between the actual Web development and effective project management processes. It is important for students to understand the triple constraints (scope, time, and cost) that must be balanced in business projects.
\end{abstract}

\section{INTRODUCTION}

C $\mathrm{n}$ the recent past, the number of unfilled IT jobs jumped from 1 million to 1.3 million (Baldwin, 1998). Each year there are more than 400,000 unfilled IT positions including programmers, systems analysts and IT specialists (Haubold, 2000). Paul Additionally, the demand for IT services is growing at 25
percent per year (Paul, 1999). This trend is even more apparent in Web development jobs. In 1994, three million people used the Internet. The number of Internet users was projected to grow to approximately 1.17 billion by 2007, and to 2.0 billion by 2010 (Internet Usage Statistics, 2007). Several factors contributed to this explosive growth: ease of publishing Web pages; relatively low cost of having a Web presence; low training needs because of the simple, link-based navigational model; ease in updating and distributing information; the platform independence of the Web; and the potential of reaching a wide audience (Forsythe, Grose, and Ratner, 1998).

The architecture of the World Wide Web has evolved to the point where large and small businesses will have to be prepared to compete with those who employ Web-enabled business models to offer better responsiveness and a lower cost infrastructure (Taylor, 1998). Consequently, experienced people with Web technology and management skills are in high demand and command high salaries (Violino, 1998). In addition to these skills, knowledge of sound project management techniques is paramount to being successful in business. "Project management provides an organization with powerful tools that improve its ability to plan, implement, and control its activities as well as the ways in which it utilizes its people and resources" (Meredith \& Mantel, 2003, pp. 4).

Purdue University Calumet's Management Information Systems (MIS) program within the School of Management produces graduates who can immediately assume responsibilities as systems analysts, database administrators, webmasters, and project managers. The primary reason for this employer confidence is that the MIS curriculum provides students with practical experience applying important concepts using popular, commercial technology. In addition, all MIS graduates are required to take a course in project management. For the Web development course discussed in this paper, project management plays a very large role. In addition to teaching students the specific technologies to use in Web development, students are presented with a structured project management process for Web site development. A major focus throughout the course is the need to balance the three project constraints: scope, time, and budget. 


\section{THE PROJECT MANAGEMENT APPROACH}

"Project management includes the processes of initiating, planning, executing, controlling, and closing a project in order to meet the project's goal" (Bunin, 2003, pp. 4). A project goal is met when the required tasks are completed to produce an agreed-upon deliverable within the established time and budget constraints (Bunin, 2003). Gido and Clements (2003) offer another definition. The refer to a project as an endeavor that is established to accomplish specific objective by completing a unique set of interrelated tasks. In their definition, Gido and Clements address the need for "effective utilization" of resources (pp. 4). This triple constraint is an important concept in project management. Although it is certainly imperative to accomplish the scope and performance requirements as dictated in the project plan, it is equally as important to complete the project within the time and budget allotted.

Students must gain the knowledge and skills necessary to get jobs in the real world upon graduation. Being able to successfully develop a Web site is only one aspect of that knowledge and skill base, however. It is therefore important that project management processes and procedures are applied to all Web development tasks. This is especially true because of the extensive need for Web development projects at this time and in the future. Students must understand how to balance the triple constraint of time, budget, and scope. They must utilize the skills necessary to balance their time and thereby their budget against the end goal of a comprehensive Web site.

Within the scope of this Web development team project, students act in the role of designers, programmers, and project managers. They must be aware of the time limitations against which they are working. Their Web design must be such that it satisfies the project criteria, but they must balance that design against the amount of time (i.e., one semester) that they have to complete the project. The instructors for the Web development course act as project supervisors throughout the semester. The instructors oversee all development and assure that project milestones are met. Additionally, they approve the Web design from the conceptual stage to a prototype and finally to a finished product.

\section{IMPLEMENTATION}

Once students have acquired fundamental Web development skills through the weekly lab assignments, and they know the recommended Web development methodology, they embark on a team-oriented, Web site development project. The project itself is divided into the following five milestones to help the students apply scope, time, and cost constraints to their deliverable:

1. Team and project selection

2. Analysis of competitors

3. Project proposal and site design

4. Prototype demonstration

5. Group Web site presentation and final folder submission

\section{Milestone 1 - Team and Project Selection Memo}

The first task is to define a student team. Teams consist of two or three students. Some team selection recommendations/guidelines/requirements follow:

- $\quad$ Team members should have compatible schedules outside of class.

- $\quad$ Students are expected to meet their team's expectations for attending team meetings, completing individual assignments, and contributing to the integration of those assignments into a cohesive team submission. Team members must make a reasonable attempt to inform their teammates of meetings and to contact their teammates if they have missed a class or a team meeting. Teams should promptly notify the instructor of attendance or performance problems.

- $\quad$ Each team member must document all of their personal activities related to the team project. The documentation will include dates, times, and descriptions of work completed and must be available to the 
instructor upon request. Team members who do not contribute adequately to the project will have their personal project grade adjusted accordingly.

The use of personal journals is an important part of the class. It is through the use of the journals that the project constraint of time is addressed. The instructors review the journal just as they would view a work $\log$ or meeting recap in a business setting, to assure that each team member is working at an equal level on the project. Students can also use the log to do a cost analysis, given a set figure for various tasks. For instance, system design work in business is generally given a higher cost than tasks associated with programming.

For this milestone, student teams submit a dated memo to the instructor that includes the team's chosen Web site as selected from a list of businesses, together with each team member's name, phone number, and e-mail address. Each member must sign this memo and all team members should have a copy of this memo.

Once the team has had their memo approved by the instructor, they will begin to create a Web site for the company. The scope of the Web site should be neither too broad nor too trivial. Again, students must balance the project constraints of time and scope when determining what to include in the scope. The teams have to find a balance that considers their schedules, the total calendar time allotted to the project (approximately 10 weeks), and their Web development skills. To abet the students in this area, the instructors define minimum web site features that constitute $75 \%$ of the project requirements. The student team determines additional relevant features to add to the site for the remaining $25 \%$ of the project. Students are not expected to build an exhaustive Web site that allows the company to conduct all of its business via the Internet. Likewise, there is little value in developing a Web site that documents a minute, unimportant, or uninteresting aspect of the company.

The minimum project requirements are objective and fairly easy to meet. These requirements include:

- $\quad$ Minimum of 7 Web pages.

- $\quad$ Site must provide at least 5 internal and 2 external Web site links.

- $\quad$ Utilize either Frames or Tables for page layout.

- $\quad$ Include at least 4 photo-quality images incorporated with fast loading.

- $\quad$ Incorporate 3 different uses of JavaScript.

- $\quad$ Utilize Cascading Style Sheets (CSS 1) for a more consistent and efficient site.

- $\quad$ Provide company contact information to the user (name, address, phone, fax, email).

- Use terminology appropriate to the user.

- $\quad$ Arrange the pages in a logical fashion.

- Include only necessary or relevant information.

- Use graphics and colors where appropriate to enhance design but not at the expense of too much load time.

- $\quad$ Site must be tested for usability in both Internet Explorer and Netscape Navigator.

- $\quad$ All standard criteria discussed in class should be utilized. Examples (not an exhaustive list): page titles, copyright statements, alt attributes and sizing for images, spelling, grammar, consistency from page to page, color use, graphics, etc.

\section{Milestone 2 - Analysis of Competitors}

It is important for students to analyze the competition of the type of business chosen for their Web development project. To this end, each student team must complete an assessment of three Web sites (and URLs) currently available for a similar business. For the successful completion of this milestone, they must discuss the benefits and/or problems with the three Web sites. They include such things such as usability, navigation, appropriateness for the topic and intended audience. Finally, they discuss which aspects of the example site might be useful and which they would change for their own Web site project. The assessment of each site should be at least one printed page. Students also attach a printout of the home page for each Web site identified. 


\section{Milestone 3 - Project Proposal}

Once the team has completed initial project planning, they must thoroughly analyze the proposed web site needs and expectations. Before they are officially allowed to develop the site, they must seek permission from the instructor by documenting their complete analysis in a project proposal. This document is written as an executive summary memo that addresses the following points:

- $\quad$ One paragraph statement of the proposal

- $\quad$ Description of the company and statement of needs for proposed Web site

- $\quad$ outline of work to be completed, including strategy methods and criteria for collecting web site data

- Justification for the Web site (potential value of the site).

- $\quad$ User profile (typical user of the Web site).

- $\quad$ Benefits to all persons (company, users).

- $\quad$ Outline of work to be completed, including strategy for collecting data.

- $\quad$ Evaluation strategy including usability testing methodologies, surveys, plans.

- $\quad$ Anticipated problems.

- $\quad$ A one page description of the design, and content of your proposed Web site.

- A graphical representation identifying the organization, layout and anticipated links.

As long as the above points are adequately addressed, permission to pursue the proposed project is granted.

\section{Milestone 4 - Initial Prototype Demonstration}

Much like any other systems development project one of the most valuable things that the teams discover is that it is difficult to keep the scope within an achievable time frame. For the prototype demonstration, a student team sits with the instructor and reviews what work has been done thus far, and what work remains. As the project supervisor, the instructor analyzes the feasibility of the students completing the project scope submitted within the given time frame.

In addition to the prototype in this milestone, student teams must include a report that describes their test strategy, including samples of the user tests, the actual data collected, and their analysis of the results. Although studies have shown that the optimum number of test users is five (Nielsen, 2000), the minimum requirement is ten. This helps the students realize trends and account for different groups of users.

\section{Milestone 5 - Team Presentation and Final Folder Submission}

During the semester, every team is developing a site for a different client with unique objectives. One of the most interesting milestones completed by the teams is a presentation of the site to the rest of the class. Every team member is required to actively participate in the presentation. Minimum content requirements are given to the students prior to their presentation. The presentations are timed. Finally, the presentations include a demonstration of the major elements of the site. Since the presentations are completed at least one week prior to the final submissions, many teams are able to get peer feedback and ideas for the additional features that can help improve the site for the client and target users.

The final deliverable for the Web site development project is the submission of the following materials in a three ring binder.

- $\quad$ Printouts of all web pages for a complete Web site that incorporates feedback from instructor, peers, and potential users.

- $\quad$ Results of the usability tests. 
- $\quad$ A one-to-two page written report describing the Web site. In this report, students discuss features that they successfully incorporated, and possible future improvements. They also describe how the contents meet the owners and users needs.

- $\quad$ Complete activity logs for each member must be submitted with the project. Failure to provide activity logs will result in a score of zero for the team member whose logs are missing.

- $\quad$ A disk containing all files relating to the site.

- $\quad$ Copies of all previously submitted materials.

\section{SUGGESTIONS FOR FUTURE RESEARCH}

Based upon the written evaluations included with the final documentation package, students find this project to be the most valuable learning experience of the course. In addition to the students learning the technical skills necessary to be Web developers, they also learn the vital role that project management plays in Web development. Students learn first-hand that they must balance the triple constraints of scope, time, and budget. Although most student teams are quite aggressive in their original Web design document, they immediately see that the time constraint prohibits them from accomplishing everything that they set out to accomplish. The original project scope is somewhat diminished once students realize that the 16 week semester is not long enough to accommodate all of the skill learning that must take place in addition to the development effort itself.

Learning a skill such as Web development makes the students very valuable in today's IT job market. Our students are able to easily get jobs because there are so many positions open, and so few people skilled in the necessary technologies. In addition, our students have learned first-hand how to balance the scope, time, and budget of a project that will help them satisfy the initial goals of a project within the very real limitations that affect all projects. Accordingly, this project serves as a mechanism for bridging business and academe.

The instructors for the course have an easier time controlling students' learning curves based on the whole project process. Since the instructors treat the Web development project as a true business venture, they can assess the success or failure of the project in the same way. Instructors rely heavily on the usability tests that the students conduct with real users in order to determine the success of the functional features of a Web development project.

\section{REFERENCES}

1. Baldwin, H. (January 13, 1998). Federal Government Tackles IT Worker Shortage. CIO Online, pp. 1. Retrieved July 19, 2001, http://www.cio.com/CIO/011398 fed.html

2. Bunin, R. Microsoft Project 2002, Thomson Course Technology: Massachusetts, 2003.

3. Forsythe, C., Grose, E., and Ratner, J. Human Factors \& Web Development, Lawrence Erlbaum Associates: New Jersey, 1998.

4. Gido, J. \& Clements, J. Successful Project Management, Thomson South-Western: Ohio, 2003.

5. Haubold, N. (January 10, 2000). Hearings to Address Tech-Worker Shortage. NetworkWorldFusion News, pp. 1. Retrieved July 19, 2001, http://www.nwfusion.com/news/2000/0110workshort.html

6. Internet Usage Statistics. (August 2007). http://www.internetworldstats.com/stats.htm

7. Meares, C., et.al. The Digital Workforce: Building InfoTech Skills at the Speed of Innovation, US Department of Commerce Technology Administration Report, June, 1999.

8. Meredith, J. \& Mantel, S. Project Management a Managerial Approach, Wiley: New York, 2003.

9. Nielsen, J. (March 19, 2000). Why You Only Need to Test With 5 Users. Jakob Nielsen's Alertbox, pp. 1. Retrieved July 19, 2001, http://www.useit.com/alertbox/20000319.html

10. Paul, L. (November 1, 1999). Get Your Creative Staffing Juices Flowing. CIO Online, pp. 1. Retrieved July 19, 2001, http://www.cio.com/archive/110199 staffing.html

11. Sano, D. Designing large-scale websites: A visual design methodology, Wiley: New York, 1996.

12. Schulz, Y. (August 18, 1997). Web Development Is Software Development. Computing Canada, pp. 1. Retrieved July 19, 2001, http://www.corvelle.com/articles/ccarticles/WEB002A.html

13. Taylor, D. Developing an E-Business Strategy, Proceedings of the Gartner Group Symposium ITXPO '98. Lake Buena Vista, Florida, October, 1998. 
14. Violion, B. 1998. 1998 Intranet/Web Managers' Salary Survey. Network Computing, pp. 1. Retrieved July 19, 2001, http://www.networkcomputing.com/918/websal98.html

\section{NOTES}

